\title{
Health Promotion Model for Improvement of the Nutritional Status of Children Under Five Years
}

\author{
Fatimah Sari ${ }^{1}$, Bhisma Murti ${ }^{1}$, Endang Sutisna S. ${ }^{1} \&$ Kusnandar $^{1}$ \\ ${ }^{1}$ Post Graduate Programme, Sebelas Maret University, Surakarta, Indonesia \\ Correspondence: Fatimah Sari, University Sebelas Maret, Jl. Ir. Sutami 36A, Surakarta 57126, Central Java, \\ Indonesia. Tel: 62-813-4531-9767. E-mail: fatimahsari.gunabangsa@gmail.com
}

Received: May 4, 2020 Accepted: May 28, 2020 Online Published: June 16, 2020

doi:10.5539/gjhs.v12n8p144 URL: https://doi.org/10.5539/gjhs.v12n8p144

\begin{abstract}
Objective: Nutrition problems in Indonesia are multidimensional problems that are influenced by several factors including economic, education, social culture, agriculture, and health. Nutrition problems reflect economic, political, and social crises as the root causes of malnutrition. This study formulates a health promotion model to improve the nutritional status of children under five years old.
\end{abstract}

Method: This type of research is quantitative with survey design and cross-sectional approach.

Result: This study produced a risk of children under five yearsexperiencing poor nutritional status with a history of illness. The risk of children under five yearsexperiencing undernourished nutritional status with strong health workers-cadre-family partnerships and strong family support. The risk of children under five years experiencing wasting nutritional status increases with a history of diarrheal disease. The risk of children under five yearsexperiencing wasting nutritional status decreases with strong health workers-cadre-family partnerships and strong family support. The risk of a child under five yearsexperiencing a stunting nutritional status increases with a history of diarrheal disease. The risk of children under five years old experiencing stunting nutritional status decreases with strong health workers-cadre-family partnerships and strong family support.

Conclusion: Nutritional status of children under five years (malnutrition, wasting and stunting) is affected directly and indirectly through the variables of family income, mother's knowledge, attitudes towards nutrition problems, environmental sanitation, social capital, health workers-cadre-family partnerships, family support, history of diarrhea disease and mother'seducation.

Keywords: promotion, nutrition status, children under five years

\section{Introduction}

Public health problems as general in developing countries including in Indonesia are micronutrient deficiencies, especially for infants and children in the first two years of life (Eichler, Wieser, Ruthemann et al., 2012). Nutrition issues which are the main concern of the world today are stunting in children under five years old.

Health Research and Development Agency of the Ministry of Health Republic Indonesia (2013) reported a prevalence of stunting at children under five years old of $37.4 \%$ meaning that $3-4$ out of 10 children under five years old in Indonesia experience short posture. Age of the first 1,000 days of life inchildren under five years old with stunting is not caused by heredity but generally by malnutrition and/or experience pain in a relatively long time. In stunting children under five years old can occur low endurance, low intelligence, and low productivity as adults. To cope with stunting in children under five years old need to be improved nutrition from the fetus in the womb, exclusive breastfeeding until the age of 6 months, and the provision of appropriate complementary food from the age of 6 months.

According to Achadi's study (2012), children who are under five years' experience a short body or stunting having lower cognitive levels, poor learning, and psychosocial achievement. Indonesia is among 17 countries out of 117 countries reviewed by the Word Nutrition Report experiencing stunting, wasting, and overweight in children under five years. The Ministry of Health (2014) and the Food Security Council (2015) report that the percentage of malnutrition problems in children under five years short (stunting $37.2 \%$ ), thin (12\% wasting), and overweight (11.9\% overweight). 
The nutritional problem is faced by all groups of people, both low economic groups and those who have a higher economic capacity. Nutritional problems are disturbances to individuals or the community caused by the unmet need for nutrients obtained from food. The problem of macro nutrition, especially the problem of lack of protein-energy, is a problem that dominates the world's attention. At the age of 15 months, nearly one-third of children in developing countries who are malnourished, namely children under five years old with stunting, children under five years thin (wasting), and malnutrition. Obstacles to growth in the womb in the first five years of life. Morbidity from nutrition in the first five years of life affects 200 million children and includes impaired cognitive function and physical capacity. One of the nutritional problems that occur in Indonesia is children under five years with stunting (S. E. Whaley, Koleilat, M. Whaley et al., 2012).

The impact of stunting in children under five years is not only felt by parents and individuals who experience it but also affects the economy and nation's development, this is because the resources of children under five years old have lower quality than human resources normal (Oktarina \& Sudiarti, 2013).

Nutrition problems reflect economic, political, and social crises as the root causes of malnutrition. While the direct cause of malnutrition is the imbalance between food intake related to infectious diseases. Lack of food intake makes the immune system is very weak, makes it easy to be infected by infectious diseases due to tropical climate, poor environmental sanitation, so that it becomes malnourished (UNICEF, 1998).

\section{Research Methods}

This type of research is quantitative with survey design andcross-sectional approach.The main purposeof this study is to formulate a health promotion model for improvement of the nutritional status of children under five years. This research was conducted at the Public Health Centre in the Municipality of Yogyakarta, Yogyakarta Special Province, Indonesia, in December 2018 - February2019.

The target population in this study were children under five years (12-60 months) who were in eight Public Health Center in Yogyakarta Municipality area with 8,902 children under five years old (Yogyakarta City Health Office, 2016). The source population in this study is mothers who have children under five years (12-60 months) who are in eight Public Health Centre in the Municipality of Yogyakarta.

The number of samples in this study was calculated using cluster sampling technique by determining the total population of children under five years (12-60 months) in Public Health Centre in the Municipality of Yogyakarta, the determination of the population is based on geographical area and data from high nutritional status figures in eight Public Health Centre in Yogyakarta Municipality in 2016. The sample was 383 children under five years old living in the working area of Public Health Centre in Yogyakarta Municipality.

The variables of this study are endogenous: family income $\left(\mathrm{Y}_{1}\right)$, mother's knowledge $\left(\mathrm{Y}_{2}\right)$, attitudes towards nutrition issues $\left(\mathrm{Y}_{3}\right)$, environmental sanitation $\left(\mathrm{Y}_{4}\right)$, family support $\left(\mathrm{Y}_{5}\right)$, diarrheal disease $\left(\mathrm{Y}_{6}\right)$ health workerscadre-family partnerships $\left(\mathrm{Y}_{7}\right)$ nutritional status of children under five years old (malnutrition, wasting, stunting) $\left(\mathrm{Y}_{8}\right)$ and exogenous variables: mother's education $\left(\mathrm{X}_{1}\right)$ and social capital $\left(\mathrm{X}_{2}\right)$. Data Analysis in this study uses path analysis in Stata 13. Path analysis is an applied form of multi-regression analysis. Path analysis uses path diagrams to help conceptualize problems or test complex hypotheses. For prediction or forecasting and estimating the value of endogenous variables based on the values of exogenous variables, the right relationship pattern is with the structural model. Direct and indirect effects can be reflected in the path coefficients which have been standardized are the regressioncoefficients.

The hypotheses in this study are: There is a direct influence on the history of diarrhea disease, health workers-cadre- family partnerships, family support for the nutritional status of children under five years old (malnutrition, wasting,and stunting). There is an indirect effect of family support through a history of diarrhea disease and environmental sanitation on the nutritional status of children under five years old (malnutrition, wasting, and stunting).

There is an indirect effect of environmental sanitation through a history of diarrhea diseases on the nutritional status of children under five years old (malnutrition, wasting, and stunting). There is an indirect effect of the health workers-cadre-family partnerships through environmental sanitation, a history of diarrhea disease, and familysupport for the nutritional status of children under five years old (malnutrition, wasting, and stunting). There is an indirect effect of family income through family support on the nutritional status of children under five years old (malnutrition, wasting, and stunting). There is an indirect effect of mother's knowledge through family support, attitudes towards nutrition problems, and family support for the nutritional status of children under five years old (malnutrition, wasting, and stunting). There is an indirect effect of social capital through family support and health workers-cadre-family partnerships on the nutritional status of children under five years 
old (malnutrition, wasting, and stunting). There is an indirect effect of attitudes on nutrition through family support for the nutritional status of children under five years old (malnutrition, wasting, and stunting). There is an indirect effect of mother's education through family income, mother's knowledge, and family support for the nutritional status of children under five years old (malnutrition, wasting, andstunting).

\section{Results}

Table 1. Characteristics of Research Samples

\begin{tabular}{|c|c|c|}
\hline Variable & Frequency (n) & Percentage $(\%)$ \\
\hline \multicolumn{3}{|l|}{ Gender of children under five years old } \\
\hline Male & 197 & 51.40 \\
\hline Female & 186 & 41.60 \\
\hline \multicolumn{3}{|l|}{ Mother's Knowledge } \\
\hline Low Mother'sKnowledge & 162 & 42.30 \\
\hline High Mother'sKnowledge & 221 & 57.70 \\
\hline \multicolumn{3}{|l|}{ Social Capital } \\
\hline Weak Social Capital & 112 & 29.24 \\
\hline Strong SocialCapital & 271 & 70.76 \\
\hline \multicolumn{3}{|c|}{ The Partnership of Healthworkers-Cadre-Family } \\
\hline Weak Partnership & 212 & 55.35 \\
\hline Strong Partnership & 171 & 44.65 \\
\hline \multicolumn{3}{|l|}{ History of Diarrhea } \\
\hline No Diarrhea & 296 & 77.28 \\
\hline Have Diarrhea & 87 & 22.72 \\
\hline \multicolumn{3}{|l|}{ Weight by Age } \\
\hline Z Score $<-2$ Sd (Malnutrition) & 129 & 33.68 \\
\hline Z Score -2 Sdup to $2 \mathrm{Sd}$ (Good Nutrition) & 254 & 66.32 \\
\hline \multicolumn{3}{|l|}{ Height by Age } \\
\hline Z Score $<-2$ Sd (Stunting) & 133 & 34.73 \\
\hline Z Score -2 Sdup to $2 \mathrm{Sd}$ (Normal) & 250 & 65.27 \\
\hline
\end{tabular}

In Table 1, it can be seen that respondents by Gender, most children under five years have gender with a male category are 197 respondents $(51.40 \%)$ and a female category are 186 respondents $(41.60 \%)$. Mothers who have children under five years old are based on work in the category of Housewives (not workers) are 255 respondents(66.60\%) and Working mothers are 128 respondents $(33.40 \%)$. Most respondents had high family income $(\geq 1,700,000), 197$ people $(51.44 \%)$ and family income respondents / low income $(<1,700,000), 186$ people $(48.56 \%)$. Most of the mothers have low education $(<$ Senior High School), as many as 267 people (69.71\%) and mothers with high education ( $\geq$ Senior High School), as many as 116 people. Most of Mother's knowledge is high, namely 221 people $(57.70 \%)$. There are also almost half of the other respondents, namely 116 people $(42.30 \%)$ with low knowledge.

The results of the analysis related to the mother's knowledge indicators have a score range of 1-10. The questionnaire to find out the mother's knowledge consists of ten questions, with the description of the answer giving a cross $(\mathrm{x})$ on one of the appropriate alternatives in the questionnaire with the correct answer was given a value of 1 and the wrong answer given a value of 0 . Of the ten existing statements, which have a score the lowest is item number 2, which is "processing vegetables daily (washed-peeled-cut)". Vegetables are one source of vitamins and minerals that function to help the absorption of nutrients in the body. Vitamins $\mathrm{B}$ and $\mathrm{C}$ are water-soluble vitamins because vitamins $\mathrm{B}$ and $\mathrm{C}$ are water-soluble vitamins so these vitamins are very soluble 
in water. If vegetables are cut first and then washed, the water-soluble vitamins (Vitamins B and C) can easily dissolve in water, compared to vegetables that are washed before being peeled and cut. This shows the importance of processing vegetables with (washed-peeled-cut) so as not to lose and the benefits of vitamins B and $\mathrm{C}$ in the body. This shows the low processing of vegetables every day bythemother.

Most respondents with strong social capital are 271 people $(70.76 \%)$ and some respondents with weak social capital are 112 people (29.24\%). The results of the analysis related to social capital indicators have a score range of $0-18$. The questionnaire to find out social capital consists of nine statements, with the answer yes (2), sometimes (1) and, no (0). Of the nine statements available, the one with the lowest score is item number 2 , which is "the village community generally trusts the seriousness of health workers in helping to overcome residents' health problems". This shows the low trust of citizens in health workers.

Most respondents with weak health workers-cadre-family partnerships are 212 people (55.35\%) and some respondents with strong health workers-cadre-family partnerships, are 171 people (44.65\%). The results of the analysis related to indicators of health workers-cadre-family partnerships have a score range of 1-40. The questionnaire to find out the health workers-cadre-family partnerships consists of eight statements, with the answer information never (1), rarely (2), sometimes (3), often (4) and, always (5). Of the eight statements available, the one with the lowest score is item 4, "Health cadres provide health assistance on training in feeding children and toddlers". This shows the low level of assistance "Health cadres in the family about providing food to children and toddlers."

Most respondents based on attitudes toward negative nutrition problems are 225 people (58.75\%) and some respondents with attitudes toward positive nutrition problems are 158 people (41.25\%). The results of the analysis related to indicators of attitudes toward nutritional problems have a score range of 1-45. The questionnaire to determine attitudes toward nutritional problems consists of nine statements, with the answer score five (5) for answers strongly agree, score four (4) for answers agree, score three (3) for answers somewhat agree, score two (2) for answers disagree and scores one (1) for answers strongly disagree. Of the nine statements available, the one with the lowest score was item 1, "attitude toward high iron intake from breast milk". This shows the low attitude towards nutritional problems regarding the high iron intake found in breast milk.

Most respondents based on high family support are 214 people $(55.87 \%)$. The results of the analysis related to family support indicators have a score range of 1-60. The questionnaire to find out family support consists of twelve statements, with the description of the answer score answers never (1), rarely (2), sometimes (3), often (4) and, always (5). Of the twelve statements available, the one with the lowest score is item 8, "What kind of Instrumental Support does the husband/family provide loans when the mother needs a loan to buy staples?" This shows the low level of family support regarding instrumental support formothers.

Most respondents based on good environmental sanitation are 315 people $(82.25 \%)$ and some respondents with poor environmental sanitation are 68 people $(17.75 \%)$. The analysis results related to environmental sanitation indicators have a score range of $0-7$. The questionnaire to find out environmental sanitation consists of seven statements, with the answer giving a cross $(\mathrm{x})$ on one of the appropriate alternatives in the questionnaire with the correct answer was given a value of 1 and the wrong answer given a value of 0 . Of the seven statements that have, which have thelowest score is item number 2, which is "Mother and family defecate in the toilet". This shows the still low environmental sanitation of mothers and families defecating in addition to the toilet.

Most respondents were based on not having diarrhea are 296 people $(77.28 \%)$ and some respondents with the diarrhea disease are 87 people $(22.72 \%)$. The results of the analysis related to indicators of the history of the diarrheal disease have a score range of $0-10$. The questionnaire to determine the history of the diarrheal disease consists of ten statements, with a description of the answer yes (2), sometimes (1) and, no (0). Of the ten statements available, the one with the lowest score is item number 1, which is "children under five years old within 1 month suffer from diarrhea". This shows that within 1 month there is still a history of diarrheal disease in children under five years old ".

Most respondents based on nutritional status of body weight according to age with good nutritional status are 254 people $(66.32 \%)$ and respondents based on nutritional status of body weight according to age with malnourished status are 129 people (33.68\%). Most respondents based on height nutritional status according to age with normal nutritional status are 250 people $(65.27 \%)$ and respondents based on height nutritional status according to age with stunting nutritional status are 133 people $(34.73 \%)$. Most respondents based on nutritional status of body weight according to height with normal nutritional status are 332 people (86.68\%) and respondents based on nutritional status of body weight according to height with nutritional status wasting are 51 
people (13.32\%).

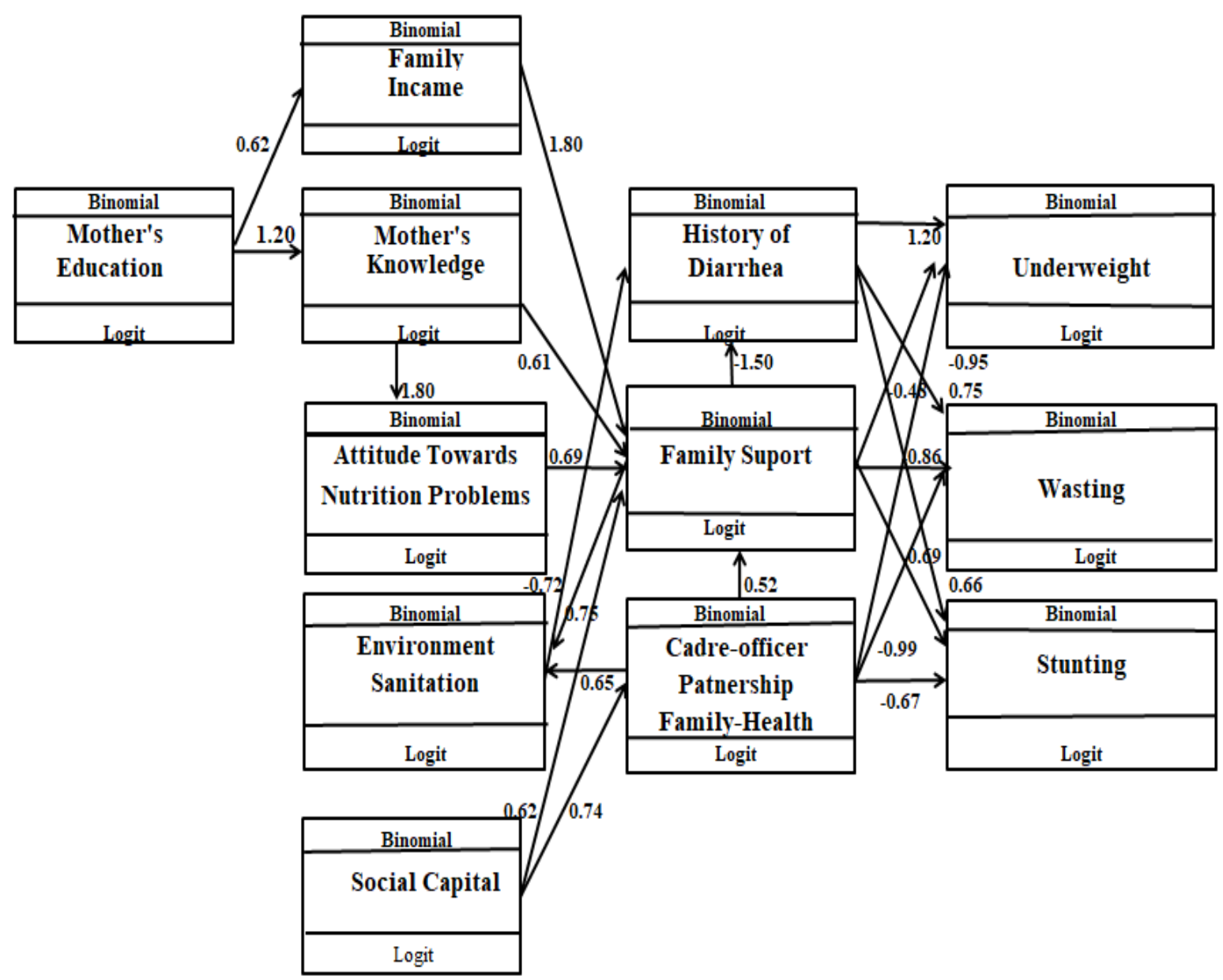

Figure 1. Path Analysis dan determinant Of Nutritional Status Diagram

Figure 1 shows that path analysis with the help of the STATA 13 program shows that there is an influence of nutritional status (malnutrition, wasting, stunting) and risk factors. The results of the coefficient on each variable in each path that there is a positive influence: mother's education of your knowledge is 1.20 , there is a positive effect of your education on family income that is equal to 0.62 , there is a positive influence of mother's knowledge of attitudes towards nutrition problems that is equal to 1.80 , there is a positive influence attitudes toward nutrition problems towards family support that is equal to 0.69 , there is a positive influence of social capital on partnerships that is equal to 0.74 , there is a positive influence of social capitalon family support that is equal to 0.62 , there is a positive influence of your knowledge of family support that is equal to 0.61 , there is a positive influence of income family to family support that is equal to 1.80 , there is a positive influence of health workers-cadre-family partnerships to family support that is equal to 0.52 , there is a positive effect of health workers-cadre-family partnershipsto environmental sanitation that is equal to 0.65 , there is a positive influence of family support on environmental sanitation that is equal to 0.75 . There is a negative influence of environmental sanitation on the history of diarrheal disease that is equal to -0.72 , there is a negative influence on family support of the history of diarrheal disease that is equal to -1.50 , there is a positive influence between the history of diarrheal disease on nutritional status (stunting) that is equal to 0.66 , there is a negative influence of health workers-cadre-family partnershipson nutritional status (stunting) that is equal to -0.67 , there is a negative influence of family support on nutritional status (stunting) that is equal to -0.99 . There is a positive influence of a history of diarrheal disease on nutritional status (malnutrition) in the amount of 1.20, there is a negative influence on health workers-cadre-family partnerships on nutritional status (malnutrition) in the amount of -0.95 , there is a negative influence on family support towards nutritional status (nutrition less) that is equal to -0.48 , there is a positive influence on the history of diarrheal disease on nutritional status (wasting) that is equal to 0.75 , 
there is a negative influence of health workers- cadre-family partnerships on nutritional status (wasting) that is equal to -0.69 , there is a negative influence on family support towards nutritional status (wasting) that is- 0.86 .

Table 2. The result from Path Analysis and Determinant of Nutritional Status

\begin{tabular}{|c|c|c|c|c|c|}
\hline \multirow{2}{*}{\multicolumn{2}{|c|}{$\begin{array}{l}\text { Dependent } \\
\text { Variable }\end{array}$}} & \multicolumn{4}{|c|}{$95 \% \mathrm{CI}$} \\
\hline & & \multirow[t]{2}{*}{$\begin{array}{l}\text { Path } \\
\text { coefficient } \\
\text { (b) }\end{array}$} & \multirow[t]{2}{*}{ Lower Limit } & \multirow[t]{2}{*}{ Upper Limit } & $\mathrm{p}$ \\
\hline \multicolumn{3}{|l|}{ Direct Influence } & & & \\
\hline \multirow[t]{3}{*}{ Malnutrition (Weight/Age) } & Family Support (Strong) & -0.48 & -0.95 & -0.10 & 0.047 \\
\hline & $\begin{array}{l}\text { The partnership of } \\
\text { healthworkers-cadre-family (Strong) }\end{array}$ & -0.95 & -1.42 & -0.46 & $<0.001$ \\
\hline & History of Diarrhea (Have Diarrhea) & 1.20 & 0.62 & 1.69 & $<0.001$ \\
\hline \multirow[t]{3}{*}{ Wasting (Weight/Height) } & Family Support (Strong) & -0.86 & -1.52 & -0.18 & 0.012 \\
\hline & $\begin{array}{l}\text { The partnership } \\
\text { healthworkers-cadre-family(Strong) }\end{array}$ & -0.69 & -1.36 & -0.02 & 0.043 \\
\hline & History of Diarrhea (Have Diarrhea) & 0.75 & 0.09 & 1.40 & 0.026 \\
\hline \multirow[t]{3}{*}{ Stunting (Height/Age) } & Family Support (Strong) & -0.99 & -1.45 & -0.52 & $<0.001$ \\
\hline & $\begin{array}{l}\text { The partnership } \\
\text { healthworkers-cadre-family(Strong) }\end{array}$ & -0.67 & -1.13 & -0.20 & 0.005 \\
\hline & History of Diarrhea (Have Diarrhea) & 0.66 & 0.13 & 1.18 & 0.014 \\
\hline \multicolumn{6}{|l|}{ Indirect Influence } \\
\hline \multirow{2}{*}{$\begin{array}{l}\text { History of Diarrhea (Have } \\
\text { Diarrhea) }\end{array}$} & Environmental Sanitation(Good) & -0.72 & -1.31 & -0.12 & 0.018 \\
\hline & Family Support (Strong) & -1.50 & -2.00 & -0.93 & $<0.001$ \\
\hline \multirow{2}{*}{$\begin{array}{l}\text { Environment } \\
\text { (Good) }\end{array}$} & Family Support (Strong) & 0.75 & 0.20 & 1.30 & 0.007 \\
\hline & $\begin{array}{l}\text { The partnership of health workers- } \\
\text { adre-family(Strong) }\end{array}$ & 0.65 & 0.06 & 1.22 & 0.028 \\
\hline \multirow[t]{4}{*}{$\begin{array}{l}\text { Family Support } \\
\text { (Strong) }\end{array}$} & $\begin{array}{l}\text { The partnership of health } \\
\text { workers-cadre-family(Strong) }\end{array}$ & 0.52 & 0.01 & 1.02 & 0.049 \\
\hline & Family Income (High) & 1.80 & 1.29 & 2.24 & $<0.001$ \\
\hline & Mother's Knowledge (High) & 0.61 & 0.09 & 1.11 & 0.019 \\
\hline & Social Capital (Strong) & 0.62 & 0.10 & 1.13 & 0.018 \\
\hline Attitudes Towards & $\begin{array}{l}\text { Attitudes Towards Nutrition Problems } \\
\text { (Positive) } \\
\text { Mother's Knowledge (High) }\end{array}$ & $\begin{array}{l}0.69 \\
1.80\end{array}$ & $\begin{array}{l}0.14 \\
1.32\end{array}$ & $\begin{array}{l}1.24 \\
2.27\end{array}$ & $\begin{array}{l}0.013 \\
<0.001\end{array}$ \\
\hline \multicolumn{6}{|l|}{ Nutrition Problems } \\
\hline $\begin{array}{l}\text { The Partnership of health } \\
\text { workers-cadre-family } \\
\text { (Strong) }\end{array}$ & Social Capital (Strong) & 0.74 & 0.27 & 1.20 & 0.002 \\
\hline Family Income (High) & Mother's Education ( $\geq$ High School) & 0.62 & 0.17 & 1.06 & 0.006 \\
\hline Mother'sKnowledge (High) & Mother's Education ( $\geq$ High School) & 1.20 & 0.66 & 1.64 & $<0.001$ \\
\hline
\end{tabular}

Table 2 presents the results of a path analysis test using the STATA 13 program. The results show that: a direct 
influence of a history of diarrheal disease on the risk of malnutrition: a history of the diarrhea disease increases the likelihood of children under five years to experience malnutrition. Children under five years with a history of diarrheal disease, have a possibility (logodd) to experience malnutrition 1.20 higher than children under five who have no history of diarrheal disease $(\mathrm{b}=1.15 ; 95 \% \mathrm{CI}=0.62$ to $1.69 ; \mathrm{p}<0.001)$.

The direct influence of family support on the risk of malnutrition: family support decreases the likelihood of children under five to experience malnutrition. Children under five years with strong family support, have the possibility $(\operatorname{logod} d)$ to experience malnutrition 0.48 lower than children under five who have weak family support $(b=-0.48 ; 95 \% \mathrm{CI}=-0.95$ to $-0.01 ; \mathrm{p}=0.047)$. The direct effect of health workers-cadre-family partnerships on the risk of malnutrition: a health workers-cadre-family partnership reduces the likelihood of children under five to experience malnutrition. Children under five years with a strong health workers-cadre-family partnership have the possibility (logodd) to experience malnutrition 0.94 lower than children under five years who have a weak health workers-cadre-family partnerships $(b=-0.94 ; 95 \% \mathrm{CI}=-1.36$ to $-0.02 ; \mathrm{p}<0.001)$.

The direct influence of a history of diarrhea disease on wasting risk: a history of the diarrhea disease increases the likelihood of children under five years to experience wasting. Children under five years with a history of diarrhea disease, have a possibility (logodd) to experience wasting 0.75 higher than children under five years who have no history of diarrheal disease $(b=0.75 ; 95 \% \mathrm{CI}=0.09$ to $1.40 ; \mathrm{p}=0.026)$. The direct influence of family support on the risk of wasting: Family support decreases the likelihood of children under five years to experience wasting.Children under five years with strong family support, have a possibility (logodd) to experience wasting 0.86 lower than children under five years who have weak family support $(\mathrm{b}=-0.86 ; 95 \% \mathrm{CI}$ $=-1.52$ to $-0.18 ; \mathrm{p}=0.012$ ).

The direct effect of ahealth workers-cadre-family partnership on the risk of wasting: a health workers-cadre-family partnership reduces the likelihood of children under the age of five to experience wasting. Children under the age of five with a strong health workers-cadre-family partnership, have a (logodd) chance of experiencing wasting 0.69 lower than children under five years who have a weak health workers-cadre-family partnership $(b=-0.69 ; \mathrm{CI} 95 \%=-1.36$ to $-0.02 ; \mathrm{p}=0.043)$. The direct influence of a history of diarrheal disease on the risk of stunting: a history of the diarrheal disease increases the likelihood of children under five years to experience stunting. Children under five years with a history of diarrhea, have a possibility (logodd) to experience stunting 0.66 higher than children under five years who have no history of diarrheal disease $(b=0.66$; $95 \% \mathrm{CI}=0.13$ to $1.18 ; \mathrm{p}<0.014$ ).

The direct influence of family support on stunting risk: family support decreases the likelihood of children under five years to experience stunting. Children under five years with strong family support, have a possibility (logodd) to experience stunting 0.98 lower than children under five years who have weak family support (b= $-0.98 ; 95 \% \mathrm{CI}=-1.45$ to $-0.52 ; \mathrm{p}<0.001)$.

The direct effect of a health workers-cadre-family partnership on stunting risk: a health workers-cadre-family partnership reduces the likelihood of children under five years to experience stunting. Children under the age of five with a strong health workers-cadre-family partnership have a possibility (logodd) to experience stunting 0.66 lower than children under five years who have a weak health workers-cadre-family partnership $(b=-0.66$; CI $95 \%=-1.13$ to $-0.20 ; p=0.005)$. The indirect effect of environmental sanitation on a history of the diarrhea disease: environmental sanitation reduces the likelihood of children under five years to have a history of the diarrhea disease. Children under five years with good environmental sanitation, have the possibility (logodd) to experience a history of the diarrhea disease 0.72 lower than children under five years who have poor environmental sanitation ( $b=-0.72 ; 95 \% \mathrm{CI}=-1.31$ to $-0.12 ; \mathrm{p}=0.018)$.

The indirect effect of family support on a history of the diarrhea disease: family support decreases the likelihood of children under five years to have a history of the diarrhea disease. Children under five years with strong family support, have a possibility $(\operatorname{logodd})$ to experience a history of diarrhea 1.50 lower than children under five years who have weak family support $(b=-1.50 ; 95 \% \mathrm{CI}=-2.00$ to $-0.93 ; \mathrm{p}<0.001)$. The indirect effect of family support on environmental sanitation: Family support increases the likelihood of children under five to have environmental sanitation. Children under five years with strong family support, have a 0.75 (logodd) probability of having better environmental sanitation than children under five who have weak family support $(b=0.75 ; 95 \%$ $\mathrm{CI}=0.20$ to $1.30 ; \mathrm{p}=0.007)$.

The indirect effect of a health workers-cadre-family partnership on environmental sanitationa health workers-cadre- family partnership increases the likelihood of children under the age of five to have environmental sanitation. Children under five years old with strong a health workers-cadre-family partnership 
have a $0.65(\operatorname{logod})$ possibility to have environmental sanitation than children under five years who have weak a health workers-cadre-family partnership $(b=0.65 ; 95 \% \mathrm{CI}=0.06$ to $1.22 ; \mathrm{p}=0.028)$. The indirect effect of a health workers-cadre-family partnership on family support: a health workers-cadre-family partnership increases the likelihood of children under five years to get family support. Children under five years with strong a health workers-cadre-family partnership have a (logodd) 0.52 higher chance of getting family support than children under five who have weak a health workers-cadre-family partnership $(\mathrm{b}=0.52$; CI $95 \%=0.01$ to $1.02 ; \mathrm{p}=$ 0.049).

The indirect effect of family income on family support: family income increases the likelihood of children under five years getting family support. Children under five years with high family income, have the possibility (logodd) to get family support 1.80 higher than children under five who have low family income $(\mathrm{b}=1.80 ; 95 \%$ $\mathrm{CI}=1.29$ to $2.24 ; \mathrm{p}<0.001$ ). The indirect effect of mother's knowledge on family support: mother's knowledge increases the likelihood of children under five years getting family support. Children under five years with high mother's knowledge, have a possibility (logodd) to get family support 0.61 higher than children under five years of age who have low mother's knowledge $(b=0.61 ; 95 \% \mathrm{CI}=0.09$ to $1.11 ; \mathrm{p}=0.019)$.

The indirect effect of social capital on family support: social capital increases the likelihood of children under five years getting family support. Children under five years of age with strong social capital, have a (logodd) chance of getting family support 0.62 higher than children under five years who have weak social capital $(\mathrm{b}=$ $0.62 ; 95 \% \mathrm{CI}=0.10$ to $1.13 ; \mathrm{p}=0.018$ ). The indirect effect of attitudes on nutrition problems on family support: Attitudes on nutrition problems increase the likelihood of children under five years getting family support. Children under five years with mothers who have attitudes toward positive nutritional problems have the possibility (logodd) to get family support 0.69 higher than children under five years who have mothers with attitudes towards negative nutrition problems $(b=0.69$; CI $95 \%=0.14$ to $1.24 ; \mathrm{p}=0.013)$.

The indirect effect of mother's knowledge on attitudes towards nutrition problems: mother's knowledge increases the likelihood of children under five years to get attitudes towards nutrition problems. Children under five yearswith high knowledge of mothershave the possibility (logodd) to get attitudes towards nutritional problems 1.80 higher than children under five years who have low knowledge of mothers $(\mathrm{b}=1.80 ; 95 \% \mathrm{CI}=$ 1.32 to $2.27 ; \mathrm{p}<0.001)$. The indirect effect of social capital on health workers-cadre-family partnership: social capital increases the likelihood of children under five years to have a health workers-cadre-family partnership. Children under five years with strong social capital, have the possibility (logodd) to have a health workers-cadre-family partnership 0.74 higher than children under five years who have weak social capital $(\mathrm{b}=$ $0.74 ; 95 \% \mathrm{CI}=0.27$ up to $1.20 ; \mathrm{p}=0.002$ ).

The indirect effect of mother's education on family income: mother's education increases the likelihood of children under five years to get family income. Children under five years with high mother's education, have the possibility (logodd) to have family income 0.62 higher than children under five years of age who have low mother's education ( $b=0.62 ; 95 \% \mathrm{CI}=0.17$ to $1.06 ; \mathrm{p}=0.006$ ). The indirect effect of mother's education on mother's knowledge: mother's education increases the likelihood of children under five years to have a mother's knowledge. Children under five years with high mother's education have the possibility $(\operatorname{logodd})$ to have 1.20 knowledge higher than children under five years who have low mother's education $(b=1.20 ; 95 \% \mathrm{CI}=0.66$ to $1.64 ; \mathrm{p}<0.001$ ).

\section{Discussion}

a. The direct influence of diarrhea history on the nutritional status of children under five years (malnutrition, wasting andstunting)

The path analysis results show that there is a positive influence on the history of diarrhea on the nutritional status of children under five years (malnutrition, wasting, and stunting) with a positive correlation coefficient. Children under five years who have underweight nutritional status have a $38 \%$ higher risk of experiencing diarrheathan children under five who have normal/good nutritional status, the nutritional status shows a low effect on the incidence of diarrhea with OR 1.38, $\mathrm{P}=0.427$ (Oketcho, Cornelio, Nyaruhucha et al., 2012).

$b$. The direct influence of family support on nutritional status of children under five years (malnutrition, wasting, and stunting).

The path analysis results show that there is a positive influence of family support on the nutritional status of children under five years old (malnutrition, wasting, and stunting) with a negative coefficient value. Social support networks include a combination of actions that are primarily aimed at maintaining the physical and psychological health of individuals. Actions in social support can be in the form of emotional, material, 
collaborative, and information support. Social support can be carried out by family, friends, neighbors, or others. When pregnancy is in a teenager, family support becomes more important because adolescents have a high risk of pregnancy weight gain and low birth weight. Family support has a positive influence on pregnancy in adolescencewhen family support is given by female families such as mothers or sisters. (Samano, Rojano, Barba et al., 2019).

c. The direct influence of the health workers-cadre-family partnershipon the nutritional status of children under five years (malnutrition, wasting, and stunting).

The results of the path analysis show that there is a positive influence of health workers-cadre-family partnership on the nutritional status of children under five years old (malnutrition, wasting, and stunting) with a negative coefficient value. Human relations are very meaningful in social life. Human relations form a social group and close collaboration between individuals and families. Partnerships facilitate knowledge transfer. Knowledge transfer is built on a comprehensive understanding and is developed through trust, commitment, interdependence, togetherness, and balanced power (He, Gallear, Ghonadian et al., 2011).

d. The indirect effect of family support through diarrheal history variables on the nutritional status of children under five years (malnutrition, wasting, andstunting).

The path analysis results show that there is a positive influence of family support through diarrheal history variables on the nutritional status of children under five years (malnutrition, wasting, and stunting) with negative coefficient values. Mothers who have strong family support are $55.87 \%$ and Mothers who have weak family support are those who have children under five years of age with nutritional status (malnutrition, wasting, and stunting) as many as $38,66 \%$. Potter (2009) states that family support is a form of providing support to family members who experience problems. Form of family support by providing maintenance support, emotional to achieve the welfare of family members, especially a mother.

e. The indirect effect of environmental sanitation through diarrheal disease history variables on the nutritional status of children under five years (malnutrition, wasting, andstunting).

The path analysis results show that there is a positive influence of environmental sanitation through a diarrheal history variable on the nutritional status of children under five years (malnutrition, wasting, and stunting) with a negative coefficient value. The incidence of diarrhea is often associated with diet and the environment. Healthy environmental sanitation will reduce the incidence of diarrhea in children under five years. The cause of diarrhea in children under five years is the healthy living habits of each family member. Healthy living habits include breastfeeding, complementary feeding, use of sufficiently clean water, use of hand washing, using latrines and properly disposing of baby's stool. Diarrhea and malnutrition are the main causes of morbidity and mortality in children under five years in areas with poor access to clean water, lack of improved sanitation, and low socioeconomic status (Araya, Tsehaye, \& Mekonen, 2018).

f. The indirect effect of family support through environmental sanitation variables on the nutritional status of children under five years (malnutrition, wasting, andstunting).

The path analysis results show that there is a positive influence of family support through family environment sanitation variables on the nutritional status of children under five years (malnutrition, wasting, and stunting) with a positive coefficient. Mothers who have strong family support are expected to have good environmental sanitation. Family support is one form of social support, where the existence of family support will create a level of success in good environmental sanitation and nutritional health status of children under five years to be good.

g. The indirect effect of the health workers-cadre-family partnershipthrough environmental sanitation variables and the history of diarrheal disease on the nutritional status of children under five years (malnutrition, wasting, and stunting).

The results of the path analysis show that there is an effect of the health workers-cadre-family partnershipthrough environmental sanitation variables and diarrheal disease history of the nutritional status of children under five years (malnutrition, wasting, and stunting) with positive coefficient values. Health with the family, in this case, is the mother will have a positive impact on the health workers-cadre-family partnership.The existence of a psychologist in the structure of the first-level health service (Puskesmas) is felt to be very important to achieve the health condition of the community perfectly. One ofpart can work together with the psychologist Puskesmas is a Posyandu's cadre because Posyandu's cadres come from the same area as the fostered area and interact daily with the community environment (Sari, 2016).

h. The indirect effect of the cadre-health-family partnership through family support variables on the 


\section{nutritional status of children under five years (malnutrition, wasting, and stunting).}

The results of the path analysis show that there is a positive influence on health workers-cadre-family partnershipthrough family support variables on the nutritional status of children under five years old (malnutrition, wasting, and stunting) with a positive coefficient. Cadres play the role of actors in a health system. Cadres provide various services at Posyandu. The services provided by the cadres include the height and weight measurements of children under five years old, filling cards for health (KMS), providing counseling/dissemination of health information, mobilizing mothers who have children under five years to attend and participate in activities Integrated Healthcare Center. The partnership between health workers and cadres and family is very important in Posyandu activities. Cadres must be fostered and enhanced their knowledge and skills through the guidance of health workers in this case the Puskesmas as a Trustee (Nilasari \& Farich, 2012).

$i$. The indirect effect of family income through family support variables on the nutritional status of children under five years (malnutrition, wasting, and stunting).

The path analysis results show that there is a positive influence on family income through the variable of family support on the nutritional status of children under five years (malnutrition, wasting, and stunting) with a positivecoefficient. The results of the study with the variable family income obtained results of family income with a high income of 51.44\%, UMK income in Yogyakarta amounting to Rp 1,700,000. Increased family income in the household will be followed by improvements in food quality for family members. Low income affects the amount of food consumed by families and increases the likelihood of contracting infectious diseases so that the nutritional status of children under five years is low. If the income is low, the food consumed does not consider nutritional value, but the value of the material is more considered (Kusumaningrum, 2003).

$j$. The indirect effect of mother's knowledge through family support variables on the nutritional status of children under five years (malnutrition, wasting, andstunting).

The path analysis results show that there is a positive influence of mother's knowledge through family support variables on the nutritional status of children under five years (malnutrition, wasting, and stunting) with a positive coefficient. Family support is important in the realization of high knowledge and positive attitudes. Family support views that someone supportive is always ready to provide help and assistance if needed. Help will be provided by the extended family and extended family as a support system for family members. Family support is given in the form of emotional, instrumental, informative, and appreciation support (Friedman, 2003).

$k$. The indirect effect of social capital through family support variables on the nutritional status of children under five years (malnutrition, wasting, and stunting).

The path analysis results show that there is a positive influence of social capital through family support variables on the nutritional status of children under five years (malnutrition, wasting, and stunting) with a positive coefficient. Social capital is one important factor that determines the economic growth of society, without the existence of harmony and synergy that will increasingly complicate the economic development of a society. To build social capital the role of groups in society is very important starting from the core group, namely the family to the community in general (Ancok, 2003).

l. The indirect effect of attitudes on nutritional problems through family support variables on the nutritional status of children under five years (malnutrition, wasting, andstunting).

The results of the path analysis show that there is a positive influence of attitudes on nutritional problems through family support variables of the nutritional status of children under five years (malnutrition, wasting, and stunting) with a positive coefficient. A mother's attitude toward positive nutrition is a factor that influences the nutritional status of children under five years. The attitude becomes a willingness which is intended to react positively or negatively to certain objects (Sarnoff, 2007).

m. The indirect effect of mother's knowledge through attitude variables towards nutritional problems on the nutritional status of children under five (malnutrition, wasting, andstunting).

The path analysis results show that there is a positive influence of mother's knowledge through the attitude variable towards nutritional problems on the nutritional status of children under five years (malnutrition, wasting, and stunting) with a positive coefficient value. Mothers who have attitudes towards negative nutrition problems with poor nutritional status are $48 \%$, while Mothers who have attitudes towards positive nutrition problems with good/normal nutritional status are $86.71 \%$. Education is a factor that influences a mother's nutritional knowledge. The more the education level a mother has, the higher one's ability to capture information can increase her knowledge (Khomsan, 2000). 
n. The indirect effect of social capital through the health workers-cadre-family partnership variable on the nutritional status of children under five years (malnutrition, wasting, andstunting).

The path analysis results show that there is a positive influence of social capital through the health workers-cadre- family partnership variable on the nutritional status of children under five years (malnutrition, wasting, and stunting) with a positive coefficient. The concept of social capital arises from the thinking that members of the community cannot individually overcome the various problems encountered. Good togetherness and cooperation from all members of the community are needed to overcome the existing problems. The basic principle of social capital which emphasizes the importance of maintaining good relations and trust between fellow citizens and with the aid providers. In this case the aid provider through a cadre of health-family-health workers (Syahra, 2003).

o. The indirect effect of mother's education through family income variables on the nutritional status of children under five years (malnutrition, wasting, and stunting).

The path analysis results show that there is a positive influence of mother's education through family income variables on the nutritional status of children under five years (malnutrition, wasting, and stunting) with a positive coefficient. The results of this study indicate that the mother's high education (Senior High School/ Vocational High School) is $30.29 \%$. The education of a mother has an important role to educate children in the family. Education isobtained using formal education but allows a mother to get an informal education. Higher education obtained by a mother makes a child shape his character and personality for the better. Research results on the study of the relationship of education level and family income towards attitudes in household waste management (case study in the village of Condongcatur, Depok, Sleman, Yogyakarta, there is a high-income family has high attitude participation towards waste management that is equal to $64.37 \%$. Low income has participation low attitudes towards waste management that are equal to $90.91 \%$ Higher education and high family income have a positive effect on family attitudes towards waste management (Putra, Taufiq, \& Juliani, 2013).

p. The indirect effect of your education through your knowledge variables on the nutritional status of children under five years (malnutrition, wasting, and stunting).

The path analysis results show that there is a positive influence on your education through the variable of your knowledge on the nutritional status of children under five years (malnutrition, wasting, and stunting) with a positive coefficient. The results of this study showed a low mother's education <senior high school by $69.7 \%$ and high mother's education $\geq$ senior high school by $30.29 \%$. Education and knowledge are the main things to change one's perception. Higher education and good knowledge of a mother can increase her knowledge about nutrition in children under five years. Nigeria in the population has limited access to formal education with a stunting prevalence in children under five years with a low education of $45 \%$ with a wasting prevalence in children under five years with a low education of $18 \%$. Mother's knowledge with low education on the prevalence of stunting in children under five yearsis $46 \%$ and mother's knowledge with low education on the prevalence of wasting in children under five years is $28 \%$. A high level of education in mothers has a positive and significant relationship to the HAZ and WHZ index in children. Anthropometric measurements in the form of percentiles and Z-scores (standard deviations). Recommendations from the results of this study are to obtain good knowledge in a mother with low education, the State of Nigeria established a health promotion program with health education through counseling (communication) for adult women. It is hoped that with this counseling adult women in Nigeria will gain knowledge and practice on nutrition, to change behavior, and reach poor women and low education in Nigeria to obtain optimal nutritional status results in children (Fadare, Amare, Mavrotas et al., 2019).

\section{Conclusion}

The risk of children under five years old experiencing malnourished nutritional status increases with a history of diarrhea. The risk of children under five years experiencing malnourished nutritional status decreases with strong health workers-cadre-family partnership and strong family support. The risk of children under five years experiencing wasting nutritional status increases with a history of diarrhea. The risk of children under five years experiencing wasting nutritional status decreases with strong cadre-health-family partnerships and strong family support. The risk of a child under five experiencing a stunting nutritional status increases with a history of diarrheal disease. The risk of children under the age of five experiencing stunting nutritional status decreases with strong health workers-cadre-family partnership and strong family support. The nutritional status of children under five years (malnutrition, wasting, and stunting) is affected indirectly through the variables of family income, mother's knowledge, attitudes towards nutrition problems, environmental sanitation, social capital, and 
mother'seducation.

\section{Research Limitations}

Limitations in this study related to the design that used, which is survey design with a cross-sectional approach, this can limit the ability to explore the causal relationship between variables. If making a comprehensive observation of the improvement of nutritional status in children under five years requires quite a long time. In this study, only questionnaires were given to the research subjects and anthropometric measurements in children under five years.

\section{Competing Interests Statement}

The authors declare that this study was written free of conflicts of interest.

\section{References}

Achadi, L. A. (2012). The First Thousand Days of Children's Life. Presented at the One Day Seminar in the framework of the 60th National Nutrition Day FKM UI, Depok.

Ancok, D. (2003). Social Capital and Community Quality. Journal of Psychological Thought and Research UII, $8(15), 4-14$.

Araya, G. W., Tsehaye, A. D., \& Mekonen, T. (2018). Risk Factors for Diarrhea and Malnutrition among children under the age of 5 years in The Tigray Region of Northern Ethiopia. International Plos One, 13(11). https://doi.org/10.1371/journal.pone.0207743

Eichler, K., Wieser, S., Ruthemann, I., \& Brugger, U. (2012). Effects of micronutrient fortified milk and cereal food for infants and children. BMC Public Health. https://doi.org/10.1186/1471-2458-12-506

Fadare, O., Amare, M., Mavrotas, G., Akerele, D., \& Ogunniyi, A. (2019). Mother's Nutrition-related knowledge and Child nutrition outcomes: Empirical Evidence From Nigeria. International Journal Plos One, 14(2), 1-17. https://doi.org/10.1371/journal.pone.0212775

Food Security Council. (2015). Strategic Food and Nutrition Policy Year 2015-2019. Jakarta.

Friedman, M. (2003). Family Nursing Theory and Practice. Jakarta: EGC.

He, Q., Gallear, D., \& Ghobadian, A. (2011). Knowledge Transfer: The Facilitating Attributes in Supply-Chain Partnerships. International Journal of Information Management Systems. 28(1). https://doi.org/10.1080/10580530.2011.536114

Khomsan, A. (2000). Nutrition Knowledge Measurement Techniques. Bogor: Bogor Agricultural University. Kusumaningrum RN. 2003. The Effect of Mother's Education Level, Mother's Economic Activity, and FamilyIncome on Toddler Nutrition Status in Simo District, Boyolali District. Thesis Faculty of Economics.SebelasMaret University. Surakarta (Published).

Ministry of Health Republic Indonesia. (2013). Guidelines for Child Nutrition Services. Directorate General of Nutrition and Maternal and Child Health: Directorate of Nutrition Development.

Ministry of Health Republic Indonesia. (2014). Balanced Nutrition Guidelines. Jakarta: Directorate General of Mother and Child Health and Development.

Nilasari, B., \& Farich, A. (2012). Relationship of Family Support and the Role of Cadres with the Participation of Elderly Participating in the Posyandu for the Elderly in MawarPosyandu, Tri Rahayu Village, Katon District, Pesawaran Regency. World Journal of Public Health, 1(3), 127-133.

Oketcho, R., Cornelio, N. M., Nyaruhucha, Taybali, S., Esron, D., \& Karimuribo. (2012). Influence of Enteric Bacteria, Parasite Infections, And Nutritional Status on Diarrhea Occurrence Among 6-60 Monts Old Children Admitted At A Regional Hospital in Marogoro, Tanzania. Tanzania Journal of Health Research, 14(2), 1-14. https://doi.org/10.4314/thrb.v14i2.3

Oktarina, \& Sudiarti. 2013. Risk Factors for Stunting in Toddlers (25-59 Months) in Sumatra. Journal of Nutrition and Food, 8(3), 175-180. https://doi.org/10.25182/jgp.2013.8.3.177-180

Potter, \& Perry. (2009). Nursing Fundamentals (Issue 7). Jakarta: SalembaMedika.

Putra, P. H., Taufiq, R. A., \& Juliani, A. (2013). Study of Relationship between Education Level and Family Income to Attitudes in Household Waste Management (Case Study in Condongcatur Village, DepokSleman, Yogyakarta). National Journal of Environmental Science and Technology, 5(2), 91-101. https://doi.org/10.20885/jstl.vol5.iss2.art3 
Samano, R., Rojano, M. H., Barba, C. G., Jimenez, S. B., Zarate, I. D., \& Ventura, R. L. A. (2019). Characteristics of the Family Support Network of Pregnant Adolescents and Its Association with Gestational Weight Gain and Birth Weight of Newborns. International Journal of Environmental Research and Public Health, 16(1222), 2-11. https://doi.org/10.3390/ijerph16071222

Sari, P. E. (2016). Community Empowerment Efforts Through the Synergy of Posyandu Cadres and Puskesmas Psychologists. Scientific Journal of Applied Psychology, 4(01), 53-61.

Sarnoff, S. (2007). Health, Stress, and Coping. Psychology Carol Wade, Carol Tavris (9th ed.). Jakarta: Erlangga

Syahra, R. (2003). Social Capital: Concepts and Applications. Journal of Society and Culture, 5(1), 1-22.

Unicef. (1998). Malnutrition: Causes, Consequences, and Solutions. The State of the World's Children.

Whaley, S. E., Koleilat, M., Whaley, M., Gomez, J., Meehan, K., \& Saluja, K. (2012). Impact of Policy Changes on Infant Feeding Decisions Among Low-Income Women Participating in the Special Supplemental Nutrition Program for Women, Infants, and Children. Public Health, 102(12), 2269-2273. https://doi.org/10.2105/AJPH.2012.300770

Yogyakarta City Health Office. (2016). Yogyakarta City Health Profile.

\section{Copyrights}

Copyright for this article is retained by the author(s), with first publication rights granted to the journal.

This is an open-access article distributed under the terms and conditions of the Creative Commons Attribution license (http://creativecommons.org/licenses/by/4.0/). 